\title{
An observational and numerical case study of a flash sea storm over the Gulf of Genoa
}

\author{
A. Orlandi ${ }^{1}$, F. Pasi ${ }^{1}$, L. F. Onorato ${ }^{2}$, and S. Gallino ${ }^{2}$ \\ ${ }^{1}$ Laboratory of Meteorology and Modelling (LaMMA) CNR-IBIMET, Firenze, Italy \\ ${ }^{2}$ Centro Funzionale Meteo-Idrologico di Protezione Civile (ARPAL CFMI-PC), Genova, Italy
}

Received: 31 December 2007 - Revised: 21 April 2008 - Accepted: 24 April 2008 - Published: 5 June 2008

\begin{abstract}
During the night between the 8 and 9 December 2006 the seawall of the Savona harbour (Liguria Region in north west of Italy) was overtopped by waves. In this work the "Savona flash sea storm" has been studied by analyzing the data recorded by meteo-marine observing stations and the data produced by high resolution meteo-marine numerical models. The data show that, due to the presence of a fast moving low pressure system, the event was characterized by a rapid transition and interaction between two different regimes of winds and related sea states.

The results of the study suggest that the most damaging dynamics of the event could be correlated to a bi-modal structure of the wave spectrum. Based on this the authors suggest that a deeper study of the spectral structure of sea storms could lead to define new operational forecasting tools for the preventive evaluation of sea storms damaging potential.
\end{abstract}

\section{Introduction}

The Gulf of Genoa is located in one of the most cyclogenetic area of the Mediterranean basin (Trigo et al., 2002), where the interaction of the synoptic flow with the complex alpine topography cause the development of deep orographic lows, which are usually very dynamic and tend to move quickly to the east driven by the upper level flow. As a consequence low level winds show a very rapid transition from "Scirocco" (south-east) to "Libeccio" (south-west), with intensity strongly enhanced by coastal effects (Onorato et al., 2006). In these cases the sea conditions are characterized by a complex crossed sea state, resulting from the superposition of wave components generated by different strong wind fetches.

In the context of one of these meteorological situations an extreme event occurred at the Savona harbour (Fig. 1a) in the night between the 8 and 9 December 2006. During such an event the harbour's seawall ( $9 \mathrm{~m}$ high from sea level) was overtopped by waves that damaged several structures on the docks (e.g. more than 100 cars damaged). This is the only reported event of this kind since 1950 (Savona Port Authority),

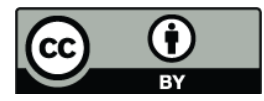

Correspondence to: A. Orlandi (orlandi@lamma.rete.toscana.it) despite the very high frequency of depressions crossing the Gulf of Genoa (about 30 a year, Trigo et al., 2002).

Hereafter we give a short description of the synoptic situation of the case under study. At 00:00 UTC of the 8 December 2006 northern and western Europe were under the influence of a vast low pressure system, formed by a very deep extra-tropical cyclone $(964 \mathrm{hPa})$ centred between the British Isles and the Norway coasts (Fig. 2a). Central Europe was affected by severe weather due to a secondary low over Britannia and the central Mediterranean sea was under the effects of a strong and extended sea level pressure gradient with consequent intense southerly winds and rough seas. During the day, as the Atlantic cyclone began to fill moving towards Norway (Fig. 2b), another secondary orographic low between the Gulf of Lion and Cote D'azur began to form (Fig. 2c). By the late afternoon the secondary low, enhanced by a strong upper level jet, moved very quickly to the Gulf of Genoa deepening to around 1000 hPa at 00:00 UTC of the 9th (Fig. 2d). As a consequence of the rapid movement of the orographic low pressure system, a strong (up to $20 \mathrm{~m} / \mathrm{s}$ ) south-easterly flow blowing along the eastern part of the Gulf of Genoa was almost immediately followed by an equally intense south-westerly flow in the western part.

The Savona harbour is located in the central part of the Gulf of Genoa (Fig. 1a), where the convergence of wind regimes resulted particularly strong on 8 and 9 December, 


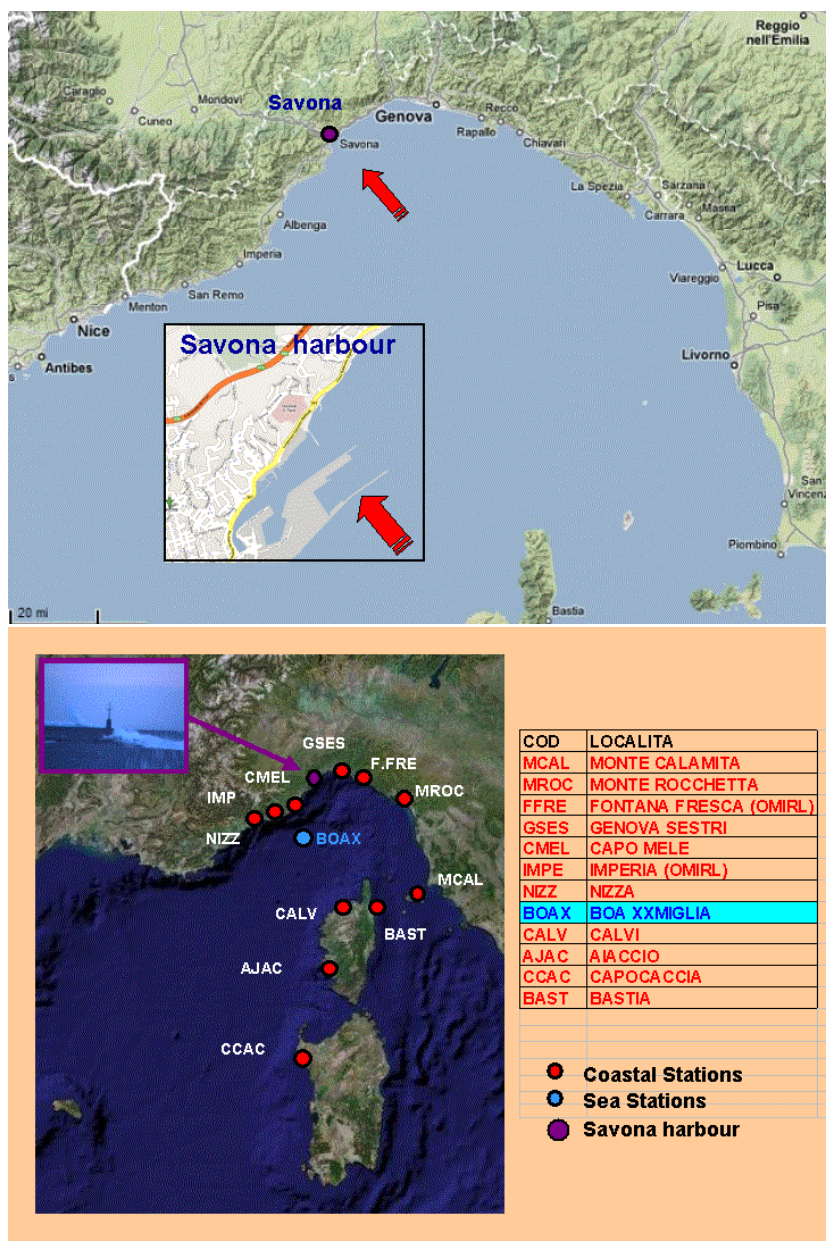

Figure 1. Map of the Gulf of Genoa (Ligurian sea, North-West of Italy) and map of Savona harbour, facing South-East (from: googleheart) (a). Map of the locations of the selected meteo-marine stations (see also Table 1) (b).

with wind gusting up to $25 \mathrm{~m} / \mathrm{s}$ and open water waves of more than $4 \mathrm{~m}$ of significant wave height. The resulting crossed sea state was characterised by a decaying rough sea from the south-east merging with an increasing south-west sea of similar magnitude.

In this work the meteo-marine conditions of the above described sea storm are studied, trough the analysis of observations and high resolution numerical models results, in order to better comprehend and describe the dynamics that might have caused the event.

\section{Data and methods}

In the study data recorded by eleven stations of the regional surface monitoring of the ARPAL CFMI-PC (Genova, Italy) and from GTS are used to characterize the sea and wind conditions. Two different types of stations are considered (Ta- ble 1; Fig. 1b): ten coastal meteorological stations (Genova Sestri - GSES - is the closest observation's site to Savona harbour) and one offshore buoy, positioned offshore Ventimiglia, in western Ligurian sea (Fig. 1b). Time series of sea state and wind data recorded by the stations are extracted for time windows covering the complete duration of the event.

In addition the met-ocean modelling chain of Tuscany Region Weather Service is used to study and describe the mechanisms underlying the event. The modelling chain is implemented and used for operational weather forecasting at La.M.Ma (Laboratory for Meteorology and environmental Modelling, http://www.lamma.rete.toscana.it) and is composed by a meteorological model and a wave model running in cascade. The former is the atmospheric model WRF-ARW (http://www.wrf-model.org, Janiic, 2003), at a resolution of $0.12 \mathrm{deg}$ with initial and boundary conditions from NCEP-GFS (T382L64) at $0.5 \mathrm{deg}$ resolution. The latter is the WW3 wave model (http://polar.ncep.noaa.gov/waves/ wavewatch/wavewatch.html, Tolman et al., 2002), running over the whole Mediterranean sea at a resolution of $0.12 \mathrm{deg}$, with a high resolution nesting $(0.02 \mathrm{deg})$ over the Ligurian sea (initial and boundary conditions are from the coarse resolution WW3 and WRF-ARW). Atmospheric initial and boundary conditions for the present study are taken from the operational run of GFS of the 00:00 UTC of the 8 December 2006, as a consequence the maximum sea storm peak of the event (00:00 UTC of the 9 December) results to be at the 24th hour of model forecast.

\section{Results}

\subsection{Observation}

The selected meteorological stations show an overall southeasterly flow between 12:00 and 24:00 UTC of 8 December and south-westerly flow between 00:00 and 12:00 UTC of 9 December (Fig. 3), with significant wind speed of more than $15 \mathrm{~m} / \mathrm{s}$ and gust up to $25 \mathrm{~m} / \mathrm{s}$ (Imperia and Genova Sestri being the most representative, showing that the south-east was stronger along the coast). The flow was characterized by a rapid change in wind direction (from about $135^{\circ}$ to about $225^{\circ}$ ) between 21:00 UTC of 8 December and 03:00 UTC of the 9 December, with a strong flux convergence between a decreasing south-easterly flow and increasing south-westerly flow. Also the wind data recorded by the French buoy near Ventimiglia (located off shore to the West of Savona) show a similar sequence of different wind regimes (southeast turning south-west) with slightly higher values $(20 \mathrm{~m} / \mathrm{s}$ and $25 \mathrm{~m} / \mathrm{s}$ ) see Fig. 4.

Regarding the sea state the French buoy reported significant wave height up to $3.5 \mathrm{~m}$ (Fig. 4) with different wave periods for the two wave components: around $6 \mathrm{~s}$ for the south-east, and $7 \mathrm{~s}$ for the south-west. In particular the southeasterly wave component shows a more rapid increase of the wave height over wave period ratio $(\mathrm{Hs} / \mathrm{T})$ with respect to the 
Table 1. Most representative meteorological stations selected from GTS and the regional network of surface stations (OMIRL) for the event of 8-9 December 2006.

\begin{tabular}{lccccccc}
\hline Station site & Code & $\begin{array}{c}\text { Station } \\
\text { type }\end{array}$ & $\begin{array}{c}\text { Short } \\
\text { name }\end{array}$ & Latitude & Longitude & $\begin{array}{c}\text { Altitude } \\
(\mathrm{m})\end{array}$ & $\begin{array}{c}\text { Distance from } \\
\text { the coast }(\mathrm{km})\end{array}$ \\
\hline Monte Calamita (I) & 16198 & GTS & MCAL & $42^{\circ} 73^{\prime}$ & $10.4^{\prime}$ & 520 & 1.2 \\
Monte Rocchetta (I) & MROC & OMIRL & MROC & $44^{\circ} 07^{\prime}$ & $9^{\circ} 93^{\prime}$ & 412 & 0.9 \\
Fontana Fresca (I) & FFRE & OMIRL & FFRE & $44^{\circ} 4^{\prime}$ & $9^{\circ} 09^{\prime}$ & 743 & 1.7 \\
Ventimiglia (I) & 16120 & OMIRL & GSES & $44^{\circ} 42^{\prime}$ & $8^{\circ} 85^{\prime}$ & 3 & 0.6 \\
Capo Mele (I) & 16153 & GTS & CMEL & $43^{\circ} 95^{\prime}$ & $8^{\circ} 17^{\prime}$ & 221 & 0.3 \\
Imperia (I) & IMPE & OMIRL & IMPE & $43^{\circ} 88^{\prime}$ & $8^{\circ} 02^{\prime}$ & 60 & 0.7 \\
Nizza (F) & 07690 & GTS & NIZZ & $43^{\circ} 65^{\prime}$ & $7^{\circ} 0^{\prime}$ & 4 & 0.3 \\
Boa Ventimiglia (F) & 61001 & GTS & BOAX & $43^{\circ} 40^{\prime}$ & $7^{\circ} 8^{\prime}$ & 3 & $40^{*}$ \\
Calvi (F) & 16522 & GTS & CALV & $40^{\circ} 57^{\prime}$ & $8^{\circ} 17^{\prime}$ & 204 & 1 \\
Aiaccio (F) & 07761 & GTS & AJAC & $41^{\circ} 92^{\prime}$ & $8^{\circ} 8^{\prime}$ & 5 & 0.5 \\
Capo Caccia (I) & 16522 & GTS & CCAC & $40^{\circ} 57^{\prime}$ & $8^{\circ} 17^{\prime}$ & 204 & 0.3 \\
Bastia (F) & 07790 & GTS & BAST & $42^{\circ} 55^{\prime}$ & $9^{\circ} 48^{\prime}$ & 10 & $0-4$ \\
\hline
\end{tabular}
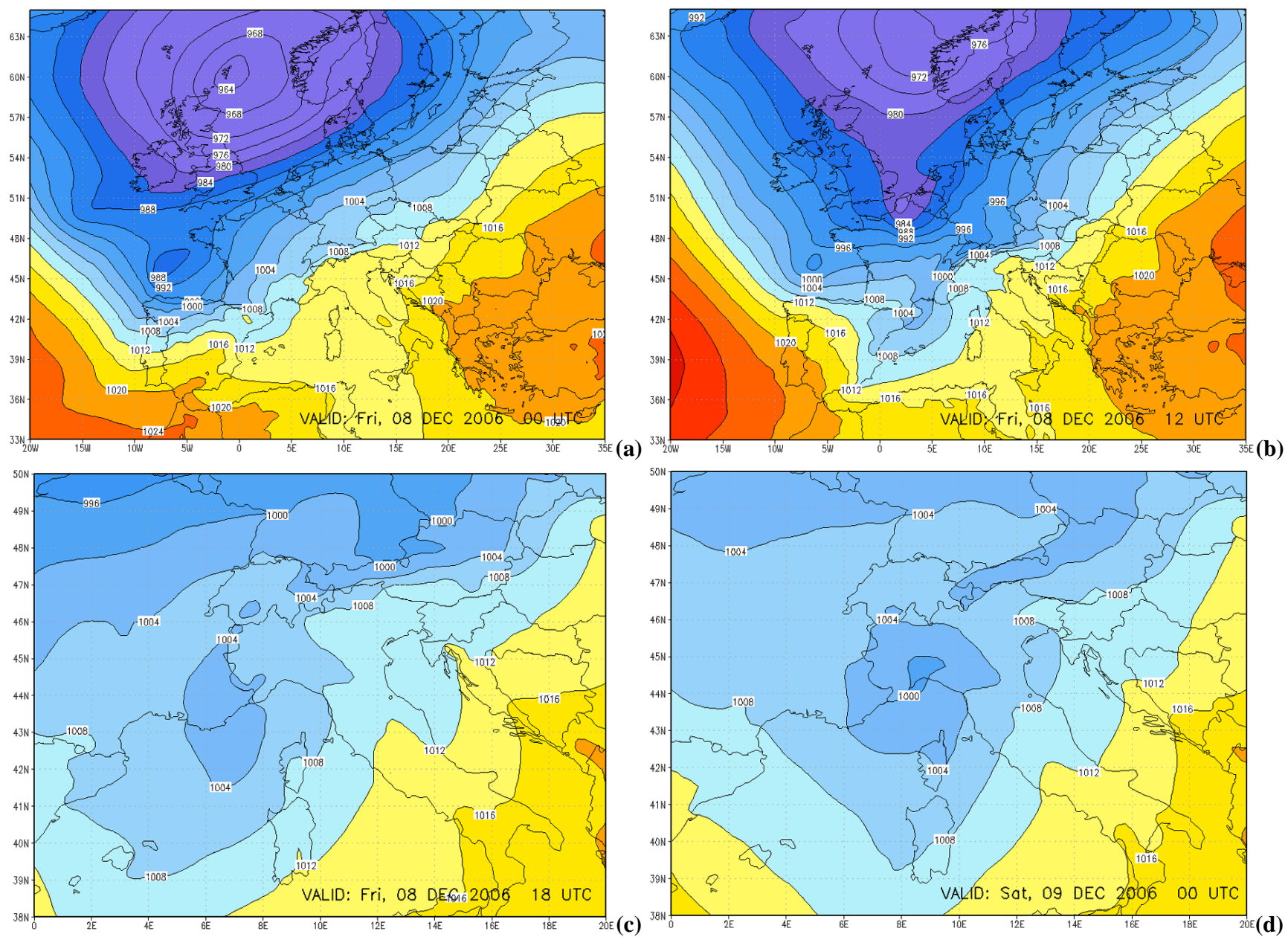

Figure 2. Maps of mean sea level pressure from ECMWF analysis valid at 08/12/2006 06:00 (a), 12:00 (b), 18:00 UTC (c) and 09/12/2006 00:00 UTC (d). Isobars are at $4 \mathrm{hPa}$ intervals. 


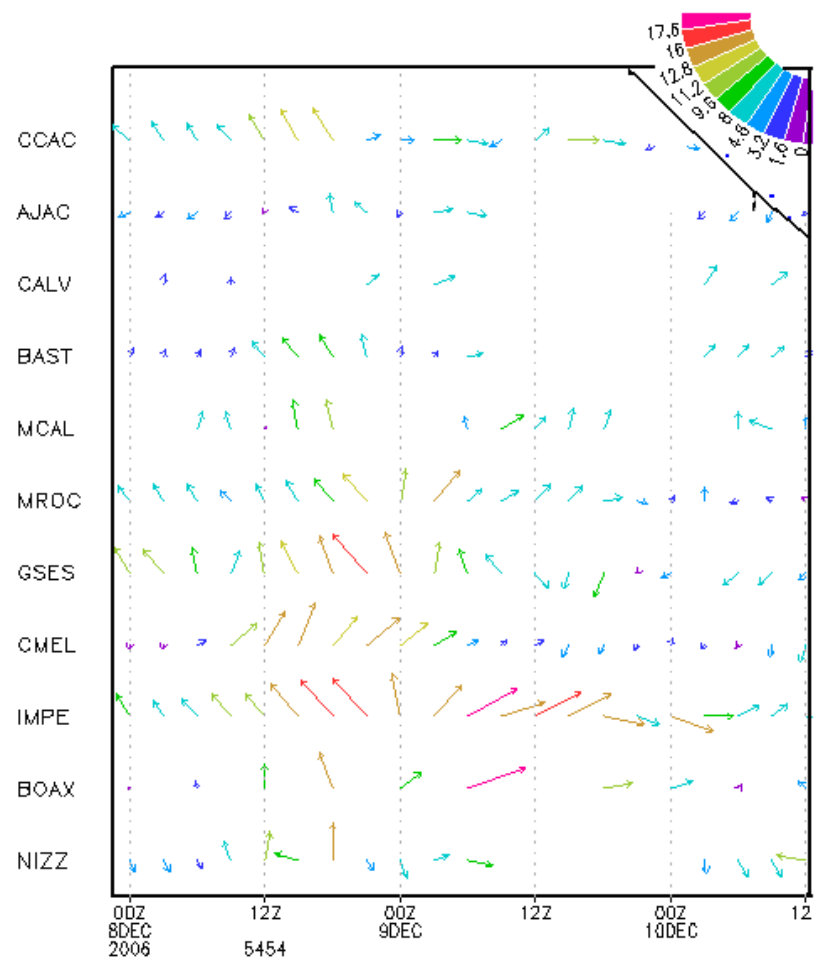

Figure 3. Wind speed trend (in $\mathrm{m} / \mathrm{s}$ ) for the selected meteorological stations. X-axis: UTC time; y-axis: labels of the selected meteorological stations (see Table 1 for correspondence to the names).

south-westerly regime, with a significant and rapid increase between 15:00 and 22:00 UTC of the 8 December.

\subsection{Numerical simulation}

The results obtained by hindcast model simulations show overall good agreement with observed data. The meteorological model WRF-ARW correctly reproduces the location and time evolution of the $10 \mathrm{~m}$ wind speed. Wind velocity is slightly over-estimated for the south-east and slightly underestimated for the south-west (against French buoy values, see Fig. 4). The WW3 wave model outputs reproduce the evolution of the two different off-shore sea states in very close resemblance with the observed one. The values of significant wave height seems over-estimated, with a greater difference for the south-west with respect to the south-east (see Fig. 5).

Regarding the events occurred in correspondence of the Savona harbour, the wave model has not given a detailed reproduction of the sudden and short lasting increase of sea state between 21:00 UTC of 8 and 00:00 UTC of 9 December, with waves overtopping the seawall ( $9 \mathrm{~m}$ high) of the Savona harbour. This is probably due to the fact that the operational wave forecasting model is aimed to forecast the offshore wave conditions and the physics implemented in it can not reproduce the near shore dynamics (Brandini et al., 2006). Nevertheless interesting features emerge from a de-

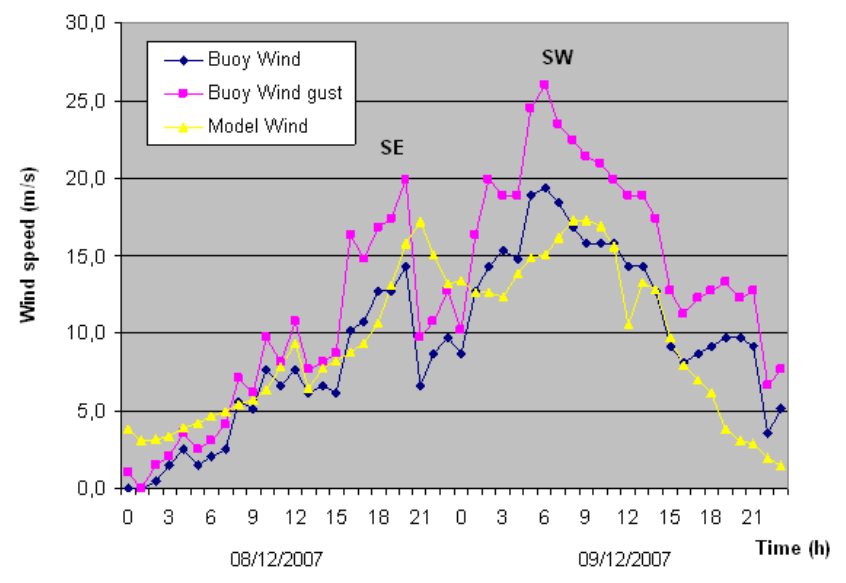

Figure 4. Ventimiglia buoy (see Fig. 1 for position). Trend of recorded wind speed and windgust versus simulated model $10 \mathrm{~m}$ wind speed. Values in $\mathrm{m} / \mathrm{s}$.

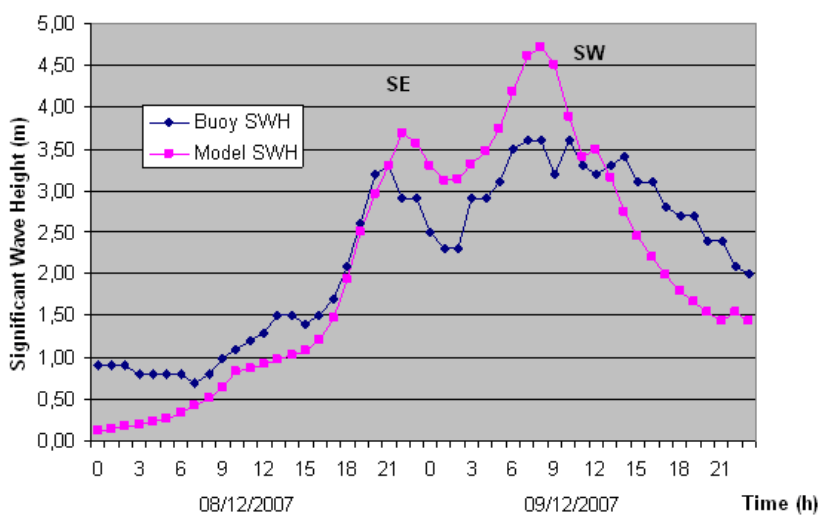

Figure 5. Ventimiglia buoy (see Fig. 1 for position). Trend of significant wave height $(\mathrm{m})$ versus simulated model wave height.

tailed analysis of the temporal evolution of the directional energy spectrum computed by the wave model. In correspondence of a selected point offshore Savona harbour the model spectrum shows a first growing broad peak centred at about $154^{\circ} \mathrm{deg}$ between 12:00 and 23:00 UTC of $8 \mathrm{De}-$ cember (Fig. 6), which suddenly splits in two much narrower peaks at 00:00 UTC of 9 December (Fig. 7). One of these two peaks corresponds to the decaying south-easterly sea, and the other growing peak corresponds to the south-westerly swell. Such a sudden change of the directional spectrum towards a bi-modal structure is well correlated in time with the flash rise of wave height that caused the major damages in Savona. This suggests that the causes of the event occurred in Savona could lay behind the complex hydrodynamic interactions between the two wave modes contemporarily impinging on the structures of the harbour. The spectral characteristics of storm events are recently gaining more and more attention also from coastal engineering community, and the bimodal structure of the wave spectrum seems to be correlated 


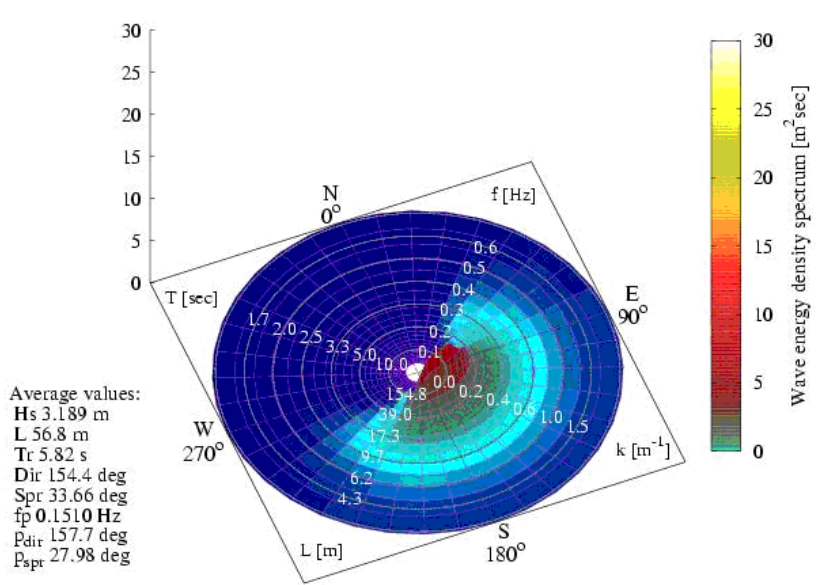

Figure 6. Model energy spectrum for a selected location in front of Savona harbour valid for 08/12/2006 18:00 UTC.

to more damaging conditions on beaches and coastal structures (Bradbury et al., 2007).

In order to better elucidate if in this case the spectral bimodality could be one of the causes of the event of the Savona harbour, our study will prosecute by adding other modelling stages by using high resolution coastal hydrodynamic modelling techniques (Booij et al., 1999; Copeland, 1985). In this way it will be possible to correctly represent the complex and non linear hydrodynamic interactions that could probably generate the conditions for the overtopping of a nine meter seawall (like the one in Savona) by an offshore sea state characterised by a significant wave height of about $4 \mathrm{~m}$.

In order to define a "bimodality index" (or also "multimodality", in the case of more than two peaks) that could be used operationally by forecasters to highlight the sea storms that could result to be the more damaging among the many occurring, the study will try to connect the modelling activities with statistical correlation analysis between the spectral structure and the amount of damage caused on coastal structures.

Another issue to be studied is the capability of fast moving low pressure systems to generate bi-modal sea wave spectra and hence to correlate also the time evolution of wind and pressure patterns to the occurrence of damaging conditions on the coast.

\section{Conclusions}

The study of a sea storm event with particular damaging consequences on Savona harbour structures, in the Gulf of Genoa (Italy) has been performed by using meteo-marine observations from coastal stations and an off-shore buoy and a meteo-marine modelling chain. Such a study showed an overall good agreement between observations and mod-

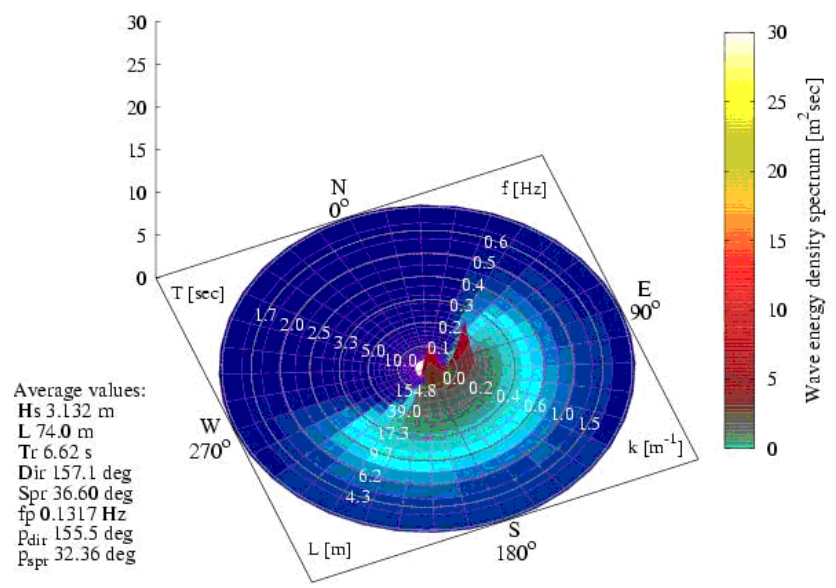

Figure 7. Model energy spectrum for a selected location in front of Savona harbour valid for 08/12/2006 23:00 UTC.

elling results, moreover the detailed study of the directional spectra computed by the wave model has shown that the most damaging conditions were characterised by a bi-modal (bi-directional) structure of wave spectra computed by the model.

This study, similarly to other recent publications, suggests that the analysis of the spectral structure of the sea state during storm events could be useful to identify the most damaging ones. From this point of view this study must be considered a preliminary work that will prosecute by refining the modelling chain with high resolution coastal hydrodynamic models, by extending the study to other storms (in order to find statistical correlations between damaging conditions and bi-modal or multimodal spectra) and to the time evolution of wind and wave patterns generated by fast moving low pressure systems. The aim of the whole work is to arrive to the definition of an operational multimodality index, based on the analysis of the forecasted spectra, that could be of help to forecasters in identifying the most probably dangerous events.

Acknowledgements. Throughout this work, we benefit from the help of our colleagues at CMIRL. Special thanks to F. Castino (for her support in graphics wind elaborations) and Alessandro Benedetti - Sasha (for his photographic contribution).

The LaMMa collaborators thank their colleagues at LaMMaCoMMa in Livorno (LaMMa center for marine meteorology) for their contributions in the implementation and maintaining of the meteocean operational chain.

Edited by: F. Stel and D. B. Giaiotti

Reviewed by: two anonymous referees 


\section{References}

Booij, N., Ris, R. C., and Holthuijsen, L. H.: A third-generation wave model for coastal regions. Model description and validation, J. Geophys. Res., 104(C4), 7649-7666, 1999.

Bradbury, A. P., Mason, T. E., and Poate, T.: Implications of the spectral shape of wave conditions for engineering design and coastal hazard assessment - evidence from the english channel, 10th International Workshop on Wave Hindcasting and Forecasting and Coastal Hazard Symposium North Shore, Oahu, Hawaii, November 11-16, abstract \# J5, 2007.

Brandini, C., Ortolani, A., Giuliani, G., Orlandi, A., and Gozzini, B.: Un sistema previsionale per il monitoraggio dellerosione costiera, Atti del Simposio "Il monitoraggio costiero mediterraneo: problematiche e tecniche di misura", Sassari, abstract \# 12, 4-6 Ottobre 2006.

Copeland, G. J. M.: A practical alternative to the "mild-slope" wave equation, Coast. Eng., 9, 125-149, 1985.
Janjic, Z. I.: A Nonhydrostatic Model Based on a New Approach, Meteorol. Atmos. Phys., 82, 271-285, 2003.

Littmann T.: An empirical classification of weather types in the Mediterranean basin and their interrelation with rainfall, Theor. Appl. Climatol., 66, 161-171, 2000.

Onorato, L., Gemelli, P., and Gallino, S.: A supervisionate classification approach of south-westerly wind regime causing severe weather over the Gulf of Genoa, EMS, abstract \# 35, 2006.

Tolman, H. L.: A third-generation model for wind waves on slowly varying, unsteady and inhomogeneous depths and currents, J. Phys. Ocean., 21, 782-797, 2006.

Tolman, H. L., Balasubramaniyan, B., Burroughs, L. D., Chalikov, D. V., Chao, Y. Y., Chen, H. S., and Gerald, V. M.: Development and implementation of wind generated ocean surface wave models at NCEP, Weather Forecast., 17, 311-333, 2002.

Trigo, I. F., Bigg, G. R., and Davies, T. D.: Climatology of Cyclogenesis Mechanisms in the Mediterranean, 130, 549-569, 2002. 